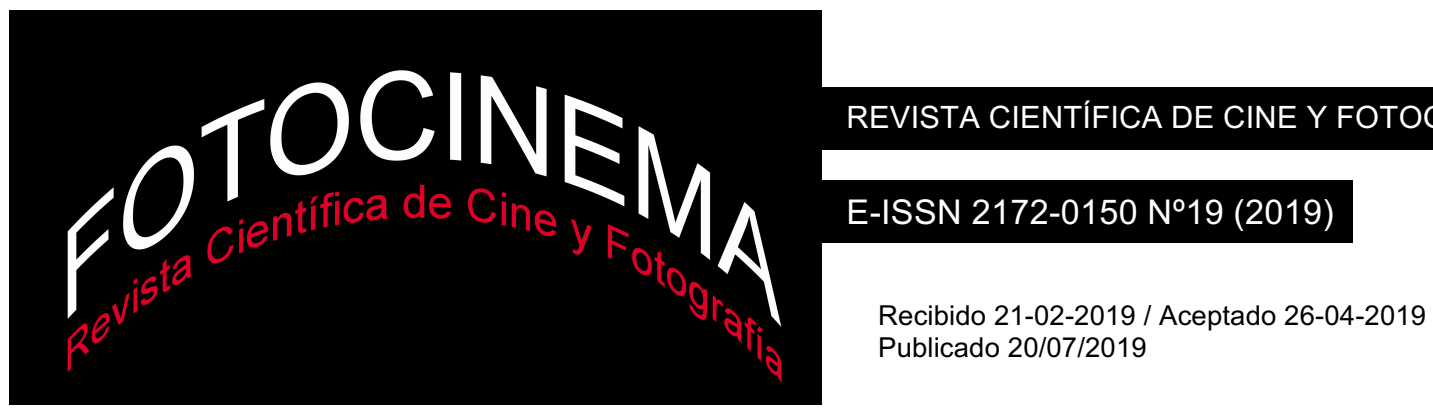

\title{
La ceguera axiológica como consecuencia de la construcción del mito. El caso de Sin perdón (1992) de Clint Eastwood
}

\section{The axiological blindness as a consecuence of the construction of the myth. The case of Unforgiven (1992) of Clint Eastwood}

\author{
Ignacio Gaztaka \\ Universidad del País Vasco/Euskal Herriko Unibertsitatea, España \\ igastaca001@ikasle.ehu.eus
}

\section{Resumen}

La sociedad americana, a fin de satisfacer su necesidad de verse entretenida a la par que moralizada, encontró en el cine la herramienta perfecta para dar solución a estas dos problemáticas. En especial, fue el wéstern, género americano por excelencia, quien se encargó, de manera simple y clara, de trasladar al gran público de los años 1920 lo que estaba bien y lo que no. Durante décadas, el wéstern ha permanecido inalterable a la evolución del cine. El motivo principal reside en su esencia: la conquista del Oeste convertida en mito; su sentido es circular, acabando siempre donde empieza, a diferencia del recorrido cronológico de avance que sigue la historia ordinaria. Entre otros muchos, Clint Eastwood ha sido un gran contribuyente de la leyenda creada en torno a la fundación de la nación americana. A lo largo de su vida, ha participado y realizado innumerables textos audiovisuales del género wéstern. Sin embargo, en Sin perdón retrata el salvaje Oeste tal y como era, haciendo entrar en contraste la cruda verdad de aquella época, con la fantasía que hasta entonces se había creado.

\begin{abstract}
The American society, in order to satisfy its need to be entertained at the same moralize, found in the cinema the perfect tool to give solution to these two problems. It was the western, an American genus par excellence, who took care, in a simple and clear way, of transferring to the general public of the years 1920 what was right and what was not. For decades, the western has remained unchanged to the evolution of cinema. The main reason lies in its essence: the conquest of the West converted into myth; Its meaning is circular, ending always where it begins, unlike the chronological journey of progress that follows the ordinary history. Among many others, Clint Eastwood has been a great contributor to the legend created around the founding of the American nation. Throughout his life, he has participated and made countless audiovisual texts of the genus western. However, in Unforgiven portrays the Wild West as it was, by contrasting the stark truth of that time, with the fantasy that had previously been created.
\end{abstract}

Palabras clave:

Realidad; ficción; wéstern; Sin perdón; Clint Eastwood; mito

Keywords:

Reality; Fiction; Western; Unforgiven; Clint Eastwood; Myth 


\section{Introducción}

Sin perdón (Unforgiven, Clint Eastwood, 1992) hace regresar a Eastwood al género que lo vio triunfar en la industria del cine, el wéstern. Esta narración pone sobre la mesa los dos principales ejes temáticos que caracterizan a este tipo de cine. Por un lado, la necesidad de un relato moralizador que, además de dar cohesión a la heterogeneidad de la sociedad americana, sirva como medio pedagógico para la población (Astre y Hoarau, 1986, p. 14). Por otro, la conquista del salvaje Oeste convertida en mito. El director californiano se apoya en los estereotipos temáticos y formales que conforman a este género. A través de ellos, proyecta sus propias reflexiones y matices sobre el origen de los Estados Unidos y de sus protagonistas.

Esta narración supone un choque directo entre la realidad y la ficción. Eastwood construye un metraje repleto de metáforas en el que la verdad que configuraba el mundo de los cowboys entra en clara contradicción con la mitificación que la literatura de su época creó. A pesar de que el relato apenas ha variado, las vías desde las que se narra sí que lo han hecho. Por ello, la aparición del séptimo arte supuso el medio perfecto para continuar con la expansión de este mito. Clint Eastwood es heredero de este legado, formando parte de la industria que ha hecho del wéstern la plataforma idónea para difundir la historia de la fundación de los Estados Unidos.

Al parecer, con Sin perdón trata de saldar su cuenta personal con la memoria histórica. En este relato, no deja de retratar aquellas figuras que fueron míticas -los pistoleros- y a los que las mitificaron -escritores y admiradores-. Eastwood parece querer sugerir, además, que la verdad de este maquillado mundo, solo puede ser desvelada a través de la violencia. Por este motivo, es en los momentos de máxima atrocidad y crueldad, donde la narración deja traslucir aquello que el mito ha pretendido ocultar.

El análisis cinematográfico aplicado en este estudio, consistente en emparejar y comparar diferentes situaciones, personajes y acontecimientos (equivalentes en peso y relevancia narrativa), ha servido como método clarificador del contenido del texto. Dicho de otro modo, el análisis textual 
consiste en descomponer el filme en sus elementos constituyentes para establecer relaciones entre tales elementos y explicar los mecanismos que les permiten constituir un "todo significante" (Gómez Tarín, 2010, p.25).

Por un lado, el protagonista, William Munny, y su respectivo antagonista, Little Bill Dagget, han sido situados al mismo nivel. En primer lugar, para dilucidar el tormento que los caracteriza y, en segundo, con la intención de resaltar sus muchas semejanzas y sus pocas diferencias. Al mismo tiempo, el estudio pone el foco de atención en los dos personajes secundarios, pero no por ello menos importantes en la riqueza que atesora el filme, el joven Scotfield Kid y W.W. Beauchamp. Estos dos hombres dan vida a aquellas personas que idolatraban a los salvajes pistoleros, eufemísticamente denominados "vaqueros".

\section{Desmitificación del wéstern}

El análisis toma aquí una línea de desarrollo, relacionada con la rama del pasado y la veracidad. En otras palabras, el mito es, en sí, un atentado contra la justicia que merecen los acontecimientos ocurridos en el pasado, pues este consiste en agrandar o exagerar ciertos detalles que marcan la diferencia entre lo que es verdad y lo que es mentira. Algunos de esos matices consisten en hacer de la conquista del Oeste una historia romántica y heroica. Eastwood toma la responsabilidad de dignificar el pasado apostando por la verdad. Zrnijewsky y Pfeiffer lo expresan perfectamente al señalar que "en el mundo de William Munny no hay gloria ni tampoco paz. No hay duelos a muerte al medio día en el centro de la ciudad. En su lugar, se ataca a los personajes cuando más vulnerables son" (Zrnijewsky y Pfeiffer, 1994, p. 173).

De hecho, los héroes de estos dramas son, a menudo, superhéroes cercanos a la divinidad. "Un hombre puede derrotar a otros cinco en un tiroteo" (Pippin, 2009, p. 226). Maria Cook explica que "en el wéstern, el papel original del héroe era proteger a los nuevos habitantes de cualquier amenaza que pudieran encontrar en su asentamiento" (Cook, 2012, p. 26). En la mayoría

\footnotetext{
${ }^{1}$ En inglés: cowboys.
} 
de los casos, el wéstern se define como el relato que hace leyenda al origen de los Estados Unidos y a la domesticación de su entorno salvaje (Hayward, 2006, p. 498 en Friedman, 2012, p. 23). En este sentido, el héroe de la frontera es una figura paterna que ha de proteger a sus hijos de las amenazas del exterior. Lo irónico de Sin perdón es que el mal nace del vientre de la comunidad, del propio sheriff Dagget. Citando a Richard Schickel, este personaje es, "in extremis, un hombre de ley y orden, y como tal no piensa tolerar ningún altercado en su ciudad” (Schickel, 2010, p. 205).

Partiendo de ese mundo mítico creado por el wéstern, Sin perdón se encarga de desvelar la verdad y estrechar el vínculo que une al pasado con la realidad. Así, la narración trata de desdibujar la línea difusa que los mitos crean y siguiendo esta línea temática, entra directamente en consonancia con una de las obras más conocidas de su género, El hombre que mató a Liberty Balance (The man who shot Liberty Valance, John Ford, 1962). Esta película planteó, de forma clara, la capa ilusoria que separa al mito de la realidad. En ella, Ransom Stoddard es retratado por la prensa como un auténtico héroe. Le atribuyen el mérito de haber asesinado al bandido que atemoriza a la población, Liberty Balance. Gracias a esa inmerecida fama, Ransom, obtiene éxito tanto en lo personal como en lo profesional. Años más tarde, tras una mirada hacia el pasado, se descubre que no fue él, sino Tom Doniphon, quien sigilosamente mató al despreciado bandido, logrando simular lo que, más tarde, la prensa redactó. Una frase de la película resume el carácter desmitificador de la misma: "Esto es el Oeste, señor. Cuando la leyenda se convierte en hecho, se escribe sobre la leyenda".

De este modo, Sin perdón recoge el testigo desmitificador de esta obra y muestra la relación simbiótica entre el hombre de palabras y el hombre de acciones (Ingrassia, 2018, p. 53). Eastwood desarrolla una narración en torno a un supuesto héroe, que combate interiormente contra la aceptación de un pasado del que no se enorgullece, a la vez que agentes mitificadores (periodistas, escritores y admiradores) crean leyendas sobre tipos que, realmente, no lo merecen. 
La narración plantea tramas que logran derrumbar los pilares temáticos que caracterizan a uno de los géneros más populares de la historia del séptimo arte, al que Eastwood tanto debe. En primer lugar, la presentación de un héroe atípico respecto al género, motivado por una causa tan poco heroica como la de matar por dinero. Seguido por la mediocridad con la que este héroe acaba con sus objetivos. Sin perdón desmonta la supuesta moralidad impecable inherente a los sheriffs, plasmando los métodos que se utilizan en Big Whiskey para mantener el orden y la paz. Por último, la desmitificación narrativa de la película alcanza la realidad de los duelos entre pistoleros, cómo se desarrollaban y la verdad que se oculta tras esa supuesta valentía.

\subsection{E 1 mito en torno al individuo}

La narración expone a dos personajes que son objeto directo de mitificación, pero de forma completamente opuesta. Uno pretende ser convertido en leyenda, ofreciendo un relato exagerado de los acontecimientos que han marcado su vida, es decir, miente para ser admirado. Este es Bob "el inglés", un hombre de origen británico, fiel súbdito de la corona. Este personaje se caracteriza por su incesante verborrea contra la república estadounidense. Acude a Big Whiskey atraído por la recompensa de las prostitutas, pero este gesto nada tiene que ver con la valentía de un auténtico caballero de la aristocracia, empeñado en resarcir el daño infligido a una joven dama, ya que lo haría sin objeto de ser recompensado. La máscara que oculta la naturaleza de Bob será arrancada burlonamente por Little Bill.

Por otro lado, el personaje que más contrasta con Bob es William Munny. Él lejos de dramatizar las atrocidades que llevó a cabo en su alocada juventud, les resta importancia. Cuando otros le preguntan si es cierto aquello que lo ha convertido en motivo de temor o admiración -según el caso- él lo niega todo. El otoñal protagonista servirá a Little Bill para demostrar, empíricamente, su teoría respecto a los duelos entre pistoleros, fundamentada en que a la hora de matar, la frialdad se superpone a la velocidad. Esto cobra sentido al final de la narración, cuando la misma los obliga a enfrentarse directamente con sus respectivos revólveres. 
Pero el primer paso es tratar de clarificar por qué Bob es un farsante con pretensiones de ser un héroe. Él llega a Big Whiskey viajando en ferrocarril, acompañado por su inseparable biógrafo, W.W. Beauchamp. Encantado con la sarta de mentiras que Bob le narra, este personaje está apunto de conocer la verdad.

El escritor decide separarse del pistolero británico poco después de llegar al pueblo. Bob es detenido por los ayudantes del sheriff, debido a que porta armas en una comunidad que lo prohíbe. Tras esto, Little Bill le propina una paliza ejemplarizante para todos aquellos cazarrecompensas que pretendan acudir a Big Whiskey, atraídos por el "oro de las putas", tal y como él lo expresa. Bob es encarcelado y ahí es, exactamente, dónde "Doble W" se debate entre la figura paternal a la que ha estado acompañando, pero que le ha mentido, y la nueva figura autoritaria que se le presenta. Esta segunda que encarna la pura verdad de la brutalidad del salvaje Oeste, sin ningún tipo de edulcorante, pues Little Bill no tiene interés en ser considerado mito.

La propia narración coloca, en dos ocasiones, a Beauchamp entre las dos figuras a las que ahora admira. Aunque, dilemáticamente, solo puede permanecer junto a una. La primera ocasión, supone el momento previo a la paliza que Little Bill le da a Bob. El biógrafo ve cómo su supuesto héroe comienza a desvanecerse, presa del miedo que siente por un tipo tan salvaje como Bill. Además de ser tan virtuoso con el revólver como Bob, Little Bill Dagget no siente compasión por matar a un supuesto "viejo amigo". Es aquí cuando Beauchamp siente el primer síntoma de haber sido engañado, pues alguien que presume de ser tan buen pistolero como Bob, no debería mostrar temor ante la presencia del sheriff de Big Whiskey.

La segunda ocasión en la que Beauchamp queda formalmente colocado entre estos personajes, ocurre una vez Bob es detenido y encarcelado. Little Bill comienza a soltar carcajadas, consecuencia de lo que está leyendo, The Duke of the death ${ }^{2}$, un nombre que hace referencia directa al supuesto título nobiliario que Bob se adjudica, pues no se sabe si es auto-atribuido (como todas las heroicidades de las que habla el libro) o realmente pertenece a la

${ }^{2}$ El duque de la muerte 
nobleza británica. Little Bill animaliza a Bob, ridiculizándolo al mismo tiempo, confundiendo el título de la novela de forma involuntaria con el de "El pato de la muerte"3. Little Bill decide humillar al viejo Bob para abrir los ojos de un engañado Beauchamp, que haciendo referencia a su miopía (F1), no ha sabido ver claramente lo que Bob en realidad es.

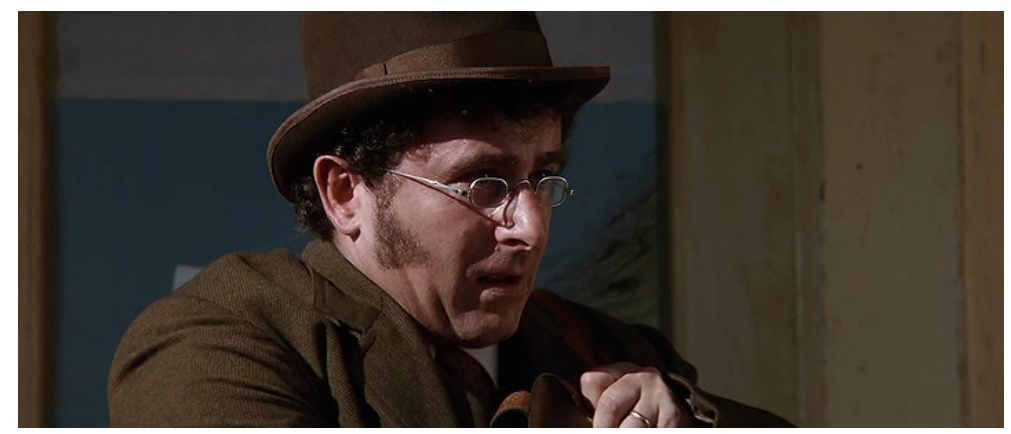

F1. Fotograma de Sin perdón

En uno de los capítulos del "Duque de la muerte", se relata cómo Bob rescata a una dama de las garras de un pistolero, llamativamente caracterizado por los dos revólveres que enfunda. Entre mofas y ante la mirada atónita de Beauchamp, Bob no sabe dónde ocultar su vergüenza cuando Bill desvela la verdad del asunto. Resulta que el "Duque” no rescató a ninguna dama. La realidad consiste en un duelo de bar entre borrachos, en el que Bob participó. La noche en la que un pistolero, cuyo mayor atributo era el de poseer un miembro más grande que el cañón del arma que portaba, fue asesinado de manera grotesca por un ebrio Bob. Celoso por no haber logrado acostarse con la supuesta dama a la que defendía, esta optó por quedarse con el hombre al que Bob asesinó. En vez de haberse enfrentado a él en condiciones parejas, Bob aprovechó que el arma de su adversario explotó en su mano (debido a un fallo del modelo) para matarle cuando estaba indefenso.

De este modo finaliza la farsa de Bob, que acompaña a la desmitificación de los duelistas de la frontera. Por ello, "Doble W" decide quedarse con Little Bill, para conocer la auténtica realidad del mundo al que acaba de llegar. En ese sentido, el fantasioso biógrafo encuentra el paradigma de su búsqueda: la encarnación del auténtico pistolero del salvaje Oeste. Este se define por su

\footnotetext{
3 Este es un chiste que cobra sentido en inglés pues las palabras duke (duque) y duck (pato) son indudablemente parecidas.
} 
dureza y templanza. Little Bill sirve a Beauchamp como mentor, pues este le ofrece al crédulo escritor muchísimo saber teórico y empírico alrededor del mundo del Oeste. Por lo tanto, no evita que el escritor se vea envuelto en situaciones de peligro y violencia. De hecho, le obliga a participar en ellas, como cuando le insta a ofrecer un revólver a Bob o, en otro momento, cuando le utiliza para redactar las respuestas que Ned suelta por cada golpe de látigo que Little Bill le propina.

W.W. parece venir de la civilización, de la costa este americana, que lleva décadas de adelanto tecnológico con respecto a la costa oeste. Por ello se ve sorprendido ante todo lo que lo rodea. Bormann expone la teoría de que en Sin perdón, el mito necesita pasar de un personaje a otro -de Bob, pasando por Little Bill, acabando en William- para permanecer en su forma metafísica, y Beauchamp es el personaje que anda detrás de esta materia incorpórea, hasta que resulta tomar cuerpo en el personaje de William Munny (Bormann, 2009, p. 3).

Tal y como el sádico sheriff explica a W.W., la clave a la hora de vencer en un duelo no consiste en la velocidad con la que uno es capaz de desenfundar y disparar al mismo tiempo (tal y como está generalizado). En la mayoría de los casos, la premura traicionará al tirador y hará que yerre en su disparo. La victoria acompaña, sin embargo, a aquél que permanece calmado y frío. Esa es la clave, la frialdad, concepto destacado a lo largo de la obra y atribuido principalmente al carácter de Will.

De esta forma, entra a colación el personaje quebrado de William Munny, respecto al diálogo entre individuo y héroe o, si se prefiere, entre realidad y mito. Nada más llegar Kid a su granja, una de las primeras cosas que le dice, lleno de admiración por querer ser como él, es que según su tío Pete, William es "más frío que la nieve, nunca le tiembla un músculo, ni tiene miedo".

Esta referencia entra en clara disonancia con lo que vemos de Will. Por ello, se convierte en objeto de desmitificación, ya que en lugar de mostrar a un carismático William Munny, atractivo en su maldad, su presentación consiste en un residuo de hombre, incapaz de acertarle a una lata con el revólver y menos aún capaz de montarse en su caballo. La transformación de Will, 
como más arriba se ha mencionado, consiste en la sed de venganza que Little Bill le provoca cuando este mata a Ned Logan, su mejor amigo. Kid ve, por fin, ante sus ojos al despiadado y sanguinario asesino del que su tío tanto le ha hablado. De hecho, tal evolución provoca en el joven admirador miedo y recelo, pues piensa que Will lo va a matar por simple crueldad.

William Munny armoniza interiormente con el asesino que lleva dentro, gracias a la botella de whiskey que se ha negado a beber a lo largo de la narración. Al final de la obra, el alcohol le aporta la valentía y embriaguez necesarias para afrontar lo que pretende llevar adelante: cabalga montado en su caballo que, al parecer, ahora sí le obedece, a lo más profundo de Big Whiskey. La noche tormentosa que envuelve a la escena simboliza el estado interior de este oscuro personaje.

El mítico asesino de mujeres, hombres y niños, capaz de volar un tren por los aires, se presenta en la taberna de Greely, ante la mirada incrédula de todos los que se hallan dentro. Comenzando por el propio Beauchamp, que está a punto de presenciar la historia de su vida. Es aquí donde lo anteriormente relatado por Little Bill cobra sentido. Cuando comienza el tiroteo en el que Will mata a todos los ayudantes del sheriff, incluido este, él permanece tranquilo, apuntando y disparando sin precipitarse. De esta manera, acierta todos sus disparos, cosa que no le ocurre a Little Bill, que, efectivamente, es traicionado por los nervios y la velocidad.

Así, William Munny enfrenta a uno de los hombres más duros del Oeste, acompañado de cuatro ayudantes, y sale ileso tras matar a todos. El mito camina por el salón del Greely y W.W. Beauchamp ha estado ahí para atestiguar lo sucedido. De esta manera, queda desmitificada la supuesta heroicidad de los hombres del Oeste. Esta narración dibuja la ceguera axiológica provocada por la bebida, además de recrear a unos simples granjeros que lo único que pretenden es ganar un dinero rápido a través de las armas.

Estos encargos de asesinato sirven para aclarar la diferencia que separa a los auténticos tipos duros de aquellos que solamente pretenden serlo. Es decir, la muerte, la violencia y los asesinatos que definen a los "verdaderos hombres" 
sirven para desenmascarar a aquellos que, por portar una pistola, creen ser tipos duros. Tal y como Little Bill le explica a Beauchamp, hace falta mucha sangre fría para matar a un hombre y mucha más cuando este va armado. Ese rasgo consiste en no respetar ni a la vida ni a la muerte y caracteriza a hombres como William, Little Bill o Bob.

\subsection{El mito en torno a la justicia}

La narración expone situaciones que desmitifican cualquier moralidad que justificase matar a un delincuente. A lo largo de la obra, se muestran dos asesinatos que quedan muy lejos de guardar cualquier tipo de relación con un acto heroico. La obra incluso llega a plantear los límites de ser merecedor o no de la pena capital. Estas muertes corresponden a la pareja de jinetes que al comienzo de la narración marcó con un cuchillo el cuerpo de Delilah; Quick Mike y Davey Boy.

Tal delito no debería ser objeto de compasión ni lástima por parte del espectador, pero la narración se encarga de mostrar ambas muertes tal y como son (o serían) en la vida real. Elimina cualquier todo tipo de edulcorante o lazo que pudiese unirlo a lo mítico. Ambos asesinatos son torpes, sucios y vergonzosos, pues los cazarrecompensas -William, Kid y Ned- no dan la posibilidad de que sus objetivos se defiendan, ya que los disparan cuando ellos no se lo esperan, es decir, a traición. Ello hace que el espectador pueda llegar a sentirse mal por la forma en la que ambos hombres son asesinados.

Por otro lado, lo lento y tortuoso de estas muertes revuelve la conciencia de los propios ejecutores. Los propios cazarrecompensas descubren de esta manera tan sanguinaria lo duro y cruel que es arrebatarle la vida a un hombre. Kid y Ned sufren lo inhumano que supone matar, pues no tiene solución y es una carga con la que uno ha de cargar para siempre. La muerte sirve para comprender quiénes son Ned y Kid (ciudadanos normales) o, mejor dicho, para descubrir quiénes no son (asesinos).

En definitiva, Sin perdón elimina cualquier atisbo de mitificación que pueda haber en quitar la vida a otro ser humano, elimina la justificación que pueda haber en impartir esa clase de justicia y expone, además, una mirada fría y 
real del arrepentimiento que ambas partes pueden sufrir al verse implicadas en este tipo de situaciones.

\subsubsection{El asesinato de Ned a Davey Boy}

Metafóricamente, el asesinato de Ned dice más sobre él de lo que a primera vista parece. Al inicio de esta secuencia, el propio personaje decide encargarse de llevar la acción a cabo. Ocultos en lo alto de unos acantilados, el trío asesino espera a que su víctima, que cabalga sin saberlo hacia un fatal destino, aparezca para ser ejecutada sin que se dé cuenta. En el momento propicio, Ned dispara, pero en lugar de acertar en Davey Boy, mata a su caballo. Al caer al suelo, el jinete queda prácticamente inmovilizado, pues tal y como se lo hace saber a sus compañeros, se ha roto una pierna en la caída.

Mientras, Kid pregunta si le han dado o no, pues, debido a su miopía, no es consciente de lo que está ocurriendo. Davey Boy trata de arrastrarse a un lugar seguro, pero apenas puede moverse. Ned vuelve a apuntarle para darle el tiro de gracia, pero resuelve que no es capaz de hacerlo, que él no es el asesino de antaño. Por ello, Will, que es al que más le urge la recompensa, toma las riendas y dispara.

La narración pone en entredicho la puntería de los cowboys del wéstern. En primer lugar, muestra a un francotirador incapaz de matar y, en segundo, un disparo que no se sabe si ha acertado en el blanco o no, hasta que la propia víctima lo confirma. Davey Boy muere desangrado, entre lloros y angustia, suplicando un poco de agua. Los gritos de lamento del joven maltratador perturban el alma de Will y Ned, veteranos de ese mundo y sabedores de lo que supone matar. No pasa así con Kid, que le reprocha merecerse lo que le ha ocurrido. Ned, por su lado, se muestra tan abatido (a nivel moral) como la víctima, ambos tirados en el suelo, sin llegar a asimilar que uno acaba de matar y que el otro va a morir.

La gran vista de Ned es, metafóricamente hablando, síntoma de su gran corazón y muestra de su profunda visión moral. Este asesinato lleva su firma, pues se ejecuta con el arma que lo define, su rifle de largo alcance. Antes de disparar y acabar con Davey Boy, comprende que ello le va a suponer una carga moral con la que antes sí sabía vivir, cuando no era más que un alocado 
bandido. Sin embargo, ahora que es un hombre de familia, maduro y feliz, simplemente no puede.

La sabiduría que la edad y la gran visión han otorgado a Ned contrastan con la ignorancia y ansias de fama que configuran al personaje del joven y miope Kid. De esta forma, se expone la otra cara de la moneda, la que enseña el dolor que supone no haber sabido evitar matar a alguien. Es decir, no haber previsto el arrepentimiento derivado de asesinar. En este sentido, es Schofield Kid quien lo prevé y quien, al igual que Ned, entiende que tampoco sirve para matar.

\subsubsection{El asesinato de Kid a Quick Mike}

$\mathrm{Al}$ igual que el primer asesinato, que servía para profundizar en el personaje de Ned, este segundo demuestra, de forma clara y directa, quién es realmente Schofield Kid. Será la violencia la que acabe por destapar lo que Ned ya había comenzado a sospechar, logrando desenmascarar a este, supuestamente, experto bandido. Schofield pretendía ser más asesino que el propio William Munny, al que admiraba y al que, al final, acaba temiendo.

Desde el momento en que se conocen, Ned pone en duda todo aquello que Kid asiente de forma tajante, cosas como que ha matado a cinco hombres. Ned encarna la mirada real y experta, frente a la fantasiosa y presuntuosa de Schofield, pues al primero lo define el saber empírico y al segundo el simple relato contado por terceros.

El choque de visiones de estos dos personajes trasciende lo ideológico, alcanzando lo puramente físico. $\mathrm{Si}$ bien, por un lado, el rasgo más significativo de Ned es su gran puntería, derivada de su magnífica visión, a Kid lo caracteriza su alta miopía, que lo habilita para ver, como máximo, en un radio de cincuenta metros. Por otro lado, sus armas los acaban de configurar a nivel plástico, ya que uno lleva un rifle de largo alcance y el otro, por el contrario, un revólver para matar a corta distancia.

Estos dos personajes no comparten nada, excepto su arrepentimiento y pesar por haber participado en los asesinatos de los dos maltratadores. La narración los expone a la desmitificación, haciéndolos sufrir mediante el remordimiento de haber asesinado, pues pretendiendo ser tipos duros 
capaces de matar por dinero, ambos terminan comprendiendo que son simples hombres, ciudadanos comunes, agentes morales.

Para ello, la obra hace a Schofield el encargado de matar a Quick Mike. Una vez muerto Davey Boy, Ned abandona el grupo y, tras esto, Will y Kid se aventuran a realizar el segundo asesinato. Este, al igual que el primero, no guarda ninguna relación que pueda hacerlo un acto digno de orgullo. En este caso, la pareja asesina espera a que su objetivo salga del refugio (en el que se oculta) para hacer de vientre. Es en ese penoso momento cuando Kid aprovecha para acercarse. Camina sigilosamente, aproximándose a la distancia necesaria para que su miopía no le estorbe. Finalmente, le dispara tres veces, a quemarropa. Este asesinato delata explícitamente la naturaleza cobarde de Kid.

Tras esto, el joven pistolero se muestra completamente desalentado, llorando, gimoteando y tirado en el suelo (al igual que Ned cuando participa en el asesinato de Mike) y al fin admite no haber matado jamás a nadie, hasta ese momento, tal y como presuponía el ya fallecido Ned. Esta imagen contrasta a nivel figurativo con la imagen del Schofield Kid que se muestra al comienzo de la narración, el cual aparece montado en su caballo. El disfraz de pistolero de Kid desaparece una vez lleva a cabo aquello que tanto anhelaba. Matar a Quick Mike le sirve de revulsivo para ver lo que realmente es, un hombre corriente. Por este motivo, decide cambiar su revólver Smith \& Wesson modelo Schofield -su antigua identidad- por una nueva, que se caracterizará por las gafas que indudablemente necesita.

Si la figura paternal de W.W. Beauchamp (Little Bill) le ha explicado de forma educada y muy teórica lo difícil que resulta matar a un hombre, la figura que le corresponde a Kid se lo explica una vez este ha cometido el atroz crimen. "Matar a un hombre es algo muy duro", le explica William Munny a su joven admirador. 


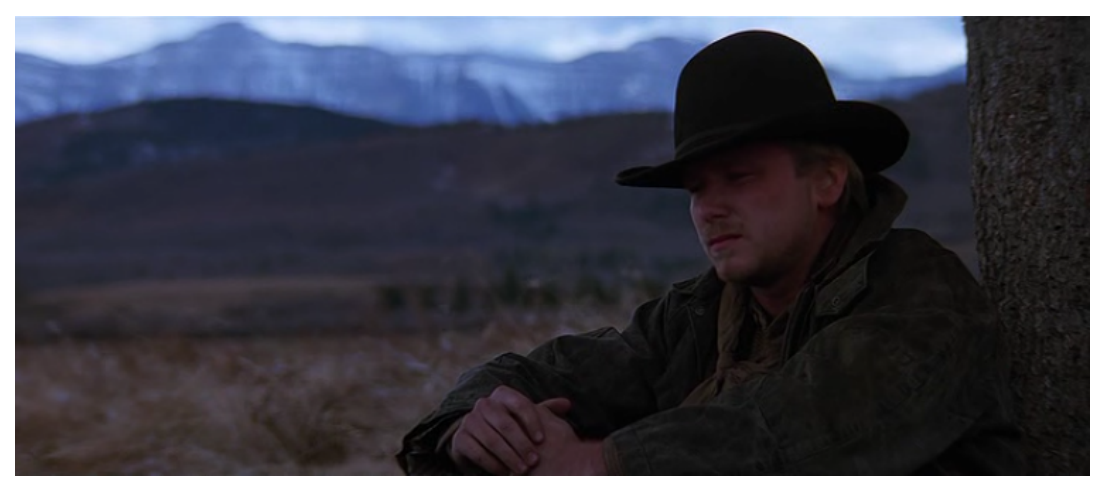

F2. Fotograma de Sin perdón

El final de esta secuencia da origen a una nueva, la última de la narración, la que relata la venganza de William Munny, que coincide, además, con el clímax de la película, pues enfrenta directamente a este personaje con Little Bill. Sirve, por añadidura, para denunciar que la base sobre la cual la comunidad americana ha establecido sus instituciones, se asienta sobre fundamentos regidos por la violencia.

\section{La espiral de violencia en Big Whiskey}

A lo largo de la obra, se exponen diferentes situaciones en las que los personajes se ven inmersos en una espiral de violencia de la que ninguno logra escapar. Desde el comienzo hasta el final, los personajes justifican el uso de la misma como garante y vehículo para la justicia. Cuando los métodos legales son ineficaces, los individuos buscan otros medios para equilibrar la balanza. Es ahí donde los sheriffs se ven fuera de situación y los asesinos y cazarrecompensas entran en juego. Otro modo de comprender la relación entre mito y violencia es la propuesta por Greenberg, en la que expone "la necesidad de la sociedad por mitificar la realidad, con el objetivo justificar actos cuestionables" (Greenberg, 1993, p. 53). Se refiere a manipular el pasado, para convertir las crueldades ya ocurridas, en leyendas para entretener.

El papel del agente dentro de la ley es, pues, evitar que la violencia se agrave. Para ello, prueba cortando de raíz el problema, golpeando a delincuentes e inocentes por igual. Siendo él, el propio sheriff, quien ejerza el máximo nivel 
de intimidación dentro de la comunidad, acaparando su papel de justiciero y el de bandido.

La consecuencia directa, es que en cuanto aparece un individuo análogo que opera fuera de los límites de la sociedad, el nivel de violencia puede adquirir cotas inimaginables. En ese sentido, la muerte es el único final para una espiral de violencia que puede alargarse indeterminadamente en el tiempo.

Esto es exactamente lo que plantea Sin perdón con el diálogo de brutalidad extrema que viven William Munny y Little Bill Dagget. Estos dos hombres, tal y como más arriba se ha expuesto, encarnan la violencia y la justicia, uno fuera de la ley y el otro dentro. Ellos dos son los responsables de que la violencia vaya a más. A William no parece importarle que Little Bill atemorice a sus ciudadanos, pues no se implica directamente en el orden social de Big Whiskey hasta que no es personalmente agraviado por Little Bill.

William Munny corta de raíz un árbol de violencia que asolaba Big Whiskey desde el comienzo de la obra. Raíz que el propio Little Bill, en vez de arrancar, ha regado con sangre y miedo. Por ello, la escena en la que Will decide beber de nuevo, tras años de sobriedad, para encaminarse a imponer su justicia, sabedor de la muerte de Ned, transcurre bajo un árbol.

Esa figura, el árbol, cobra un significado especial en esta película, pues abre y cierra la narración, dándole a esta una estructura circular, que oculta además otros elementos relacionados con la espiral de violencia. El propio sheriff Dagget es motivo del nacimiento y la muerte del terror de Big Whiskey, por ello el atardecer condiciona el nacimiento y final de la obra, dándole a la misma una pincelada cíclica a la narración.

Por otro lado, Sally, la mujer de Ned, lleva el sobrenombre de "Dos Árboles", los mismos que abren y cierran formalmente la película. Desde el primer momento en que Sally es presentada, mira con recelo a William Munny. Ella augura, y no sin razón, que este encierra un mal presagio. Le basta con mirar la escopeta que William oculta en la montura de su caballo para saberlo. A Sally "Dos Árboles" se le atribuye la cualidad de amante y protectora de la naturaleza, tanto a nivel físico -por eso lidera un hogar en perfecta armonía 
con su entorno- como metafórico. Ella es capaz de presentir lo que otros no pueden, percibe la naturaleza interior de cada uno, por eso convive con un hombre moral, que no es capaz de matar, como Ned. Al mismo tiempo, detesta a su amigo Will que, aunque intente luchar contra sus instintos, su naturaleza asesina no le permite cambiar del todo.

Por otro lado, Sally otorga un sentido circular al personaje de William Munny, refiriendo su nombre al árbol que la narración nos ofrece al abrir y cerrar la obra. Es decir, William nace asesino. Al crecer, años más tarde, en la primavera de su vida, conoce a Claudia, que intenta convertirlo en un hombre de familia. Cuando ella muere, Will se queda solo con sus hijos. Al final, su evolución como personaje consiste en recuperar su esencia natural, volviendo a ser el asesino que lo define desde que nació, cerrando de este modo su círculo personal.

Sara Anson Vaux comprende que la realidad, en esta versión del Oeste, "no es simplemente lo que se forma y se cuenta sobre el pasado o lo que se forma y se escribe, sino también lo que las leyendas del Oeste revelan sobre la naturaleza humana” (Anson Vaux, 2012, p. 68), esta visión la encarna el personaje de Sally “Dos Árboles”.

Complementando el significado de Sally, la narración utiliza otra vía para transmitir, de forma muy sugerente, la estructura cíclica de la obra. Esta consiste en el diseño urbanístico del pueblo en el que desarrollan las acciones más salvajes y sanguinarias de la obra, Big Whiskey. No es casual que este pueblo tenga dos entradas (o dos salidas) de acceso. Esto queda sugerido mediante los dos letreros que especifican que no se pueden portar armas dentro de los límites de la comunidad (F3) (F4). Así, se quiere significar que existen dos caminos para acceder a este pueblo. Edward Buscombe propone la idea de un posible "gazapo" (2004, p. 25) o, dicho de otro modo, despiste en la continuidad formal de la obra, por ello que los carteles sean distintos. 


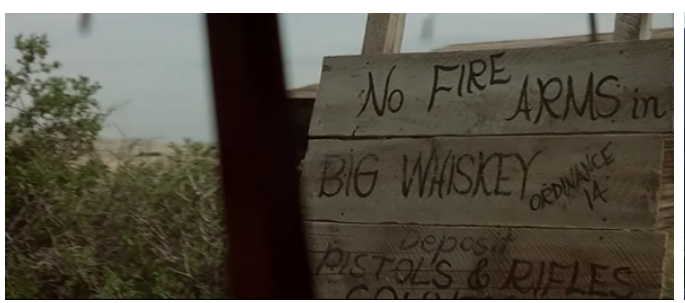

F3. Fotograma de Sin perdón

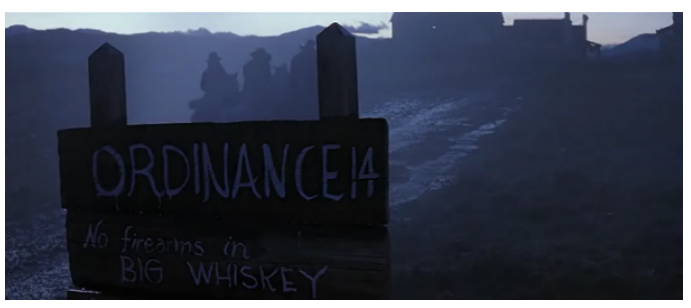

F4. Fotograma de Sin perdón

De hecho, es más que llamativo el hecho de que Bob y Will no coincidan dentro de Big Whiskey, pues al tiempo que un cazarrecompensas sale, -Bob "el inglés"- otro llega, William Munny. Ambos pistoleros se ven en el ferrocarril, vehículo que conecta al espacio dominado por la naturaleza con el que pertenece a la sociedad. Sin embargo, esta pareja de pistoleros no comparte el mismo espacio en ningún momento. Bob duerme dentro del vagón, convaleciente por la paliza que recientemente ha recibido. Will, por su lado, también se encuentra débil, debido a la tormenta que le está causando una gripe muy fuerte. Parece que la obra no permite que Big Whiskey se libre de los cazarrecompensas, pues si bien uno se marcha por un lado, un segundo llega por el otro. De esta manera, la espiral de violencia nunca desaparece.

La propia puesta en escena sitúa a los personajes de forma que dibujen círculos, emulando a la espiral la violencia. Esto ocurre cuando los hombres del sheriff se colocan en torno a Little Bill en la escena que planean salir a cazar a William Munny, cuando los mismos agentes rodean a Bob o, por último, en la secuencia en la que los protectores de Quick Mike juegan a las cartas.

Al final, Will vuelve a su hogar tras colmar su venganza matando a Little Bill. $\mathrm{Al}$ marcharse, el ciclo de la violencia renace con cada amanecer, sin que nadie sea capaz de desenterrar las profundas raíces que han arraigado a la sociedad americana.

\section{La comunidad americana y Big Whiskey}

Volviendo a la espiral de violencia que William Munny se encarga de cortar al final de la narración, Sin perdón plasma, de este modo tan radical, la 
denuncia que hace contra el mito de la conquista del salvaje Oeste y su consiguiente fundamento de la civilización americana. Sin embargo, Sin perdón trata de dejar esta teoría por los suelos. Esta película ofrece un punto de vista más fiel a la realidad. Aquí se expone que los hombres de la ley, los encargados de asegurar los pilares democráticos y republicanos que definen a la sociedad americana, son unos simples individuos violentos que imponen su norma a punta de pistola. No es casualidad que la narración haga coincidir la despiadada paliza que el sheriff Dagget propina a Bob "el inglés" con una fecha tan señalada en los Estados Unidos como es el 4 de julio, día en que se celebra la independencia de su nación del yugo del Imperio Británico. La narración logra simbolizar mediante esta dura secuencia, "la violencia demente y la rabia asesina a la partida de nacimiento de una nación" (Benoliel, 2007, p. 59).

Una de las características más reseñables del género americano es la figura del héroe de la frontera. Generalmente, este consiste en un hombre que pone su conocimiento del mundo salvaje al servicio de la comunidad. En otras palabras, la crudeza que supone sobrevivir en la naturaleza, es utilizada por el héroe de la frontera con el objetivo de garantizar la paz y prosperidad a los habitantes del entorno domesticado, la sociedad. No obstante, lo paradójico de su caso es que a pesar de sacrificarse por la comunidad, el héroe de la frontera no tiene cabida en ella. Al igual que el simple bandido, él pertenece al entorno salvaje. Por esta razón es capaz de hacerle frente a los malvados.

La frontera que separa ambos mundos es, por ello, moral. Es decir, señala lo que está bien de lo que está mal, lo que es correcto de lo que no lo es. Dentro de la comunidad, el ser humano ofrece lo mejor de sí, es un agente virtuoso. Es fuera de ella, en el entorno salvaje, donde los humanos se bestializan, compiten y combaten.

Lo irónico de Sin perdón y, por eso mismo, más reseñable, es que la figura del bandido resulta ser la del propio sheriff que, siendo teóricamente el encargado de velar por la seguridad, resulta ser aquél que rompe con la paz y libertad necesarias para cimentar la convivencia. De este modo, es necesaria la irrupción de un agente externo que se sacrifique y devuelva el orden. 
No obstante, no hay que olvidar que lo que incita a William Munny a acabar con Little Bill no es el hecho de devolver a Big Whiskey su supuesto equilibrio social, anteriores a los cortes que Quick Mike y Davey Boy produjeron en Delilah. Tal y como más arriba se ha expuesto, William venga la muerte de Ned asesinando al sheriff que lo ha matado a él. La propia forma en la que William da comienzo a su venganza desmitifica al héroe que llega a una comunidad para solventar sus problemas, ya que rompe con la primera norma del héroe de la frontera: disparar contra un hombre desarmado (Tibbets, 1993, p. 10). William aparece en la taberna de Greely's y dispara contra Skinny, sin tener oportunidad alguna de defenderse. Para Gonzálvez Vallés el tema central de la narración consiste en eso exactamente, en "la deconstrucción de la violencia mostrando incluso la crueldad del bueno de la película, contra un enemigo desarmado" (2013, p. 524).

\section{Conclusiones}

Esta investigación propone que la narración sirve para deconstruir el wéstern, en general, y su figura heroica, en particular. William es un héroe cuyo objetivo de subsanar el desorden de una comunidad no pasa de ser algo meramente secundario y circunstancial. De no haber sido Ned asesinado, él se hubiese ido de Big Whiskey, dejándolo en la miseria social y temor a la autoridad en la que vivía. Así, Sin perdón dibuja a un nuevo héroe de la frontera, que lejos de buscar matar al agente perturbador de la paz, por el bien de la comunidad, lo hace para vengar la muerte sádica a la que se ha expuesto a su amistad.

Definitivamente, esta narración busca desmitificar la figura de los hombres del wéstern. Al mismo tiempo, trata de denunciar que, en la comunidad de los Estados Unidos, lo que diferencia a un sheriff de un bandido, es el lado en el que sirve a la ley. Will utiliza la violencia para corregir males específicos, mientras que Little Bill la usa para afirmar su propio ego (Babiak, 1998, p. 63). Esta perspectiva del texto fílmico es captada, paradójicamente, por los dos miopes de la narración, que al abrir los ojos y darse cuenta de la realidad, huyen asustados por lo que el mito no les dejaba ver. 
Los ciudadanos corrientes, las buenas personas, lejos de vivir en una democracia parlamentaria, han de lidiar con un sistema en el que cualquiera, a golpe de puñetazo o punta de pistola, puede imponer justicia. Eso es de lo que se burla Bob desde el primer momento en que aparece. En la sociedad americana parece no existir ningún reparo con el hecho de matar a un presidente, pues en veinte años 4 ya han matado a dos. Bob declara, y parece ser, en cierto modo, la voz que encarna la temática de la narración, que Estados Unidos, lejos de ser una civilización moral y envidiable -tal y como lo dibuja el wéstern clásico- es una sociedad violenta y salvaje.

Por esto mismo, la narración ofrece un plano muy significativo. En él se muestra a William Munny, montado en su caballo, con la bandera de los Estados Unidos hondeando tras él [F5], imponiendo una nueva ley a los habitantes de Big Whiskey. Una vez muerto Little Bill, el nuevo agente de la justicia amenaza con acabar con cualquiera que vuelva a maltratar a una prostituta. Cabe rescatar aquí a Buchanan, que propone que, el wéstern, en general, y Sin perdón, en particular, rastrea la fundación de las leyes de la frontera (Buchanan, 2005, p. 106). La narración parece querer decir que es así, mediante el método de la sangre, la pólvora y el miedo, como en realidad se han echado raíces en el suelo americano y se ha cimentado esta sociedad.

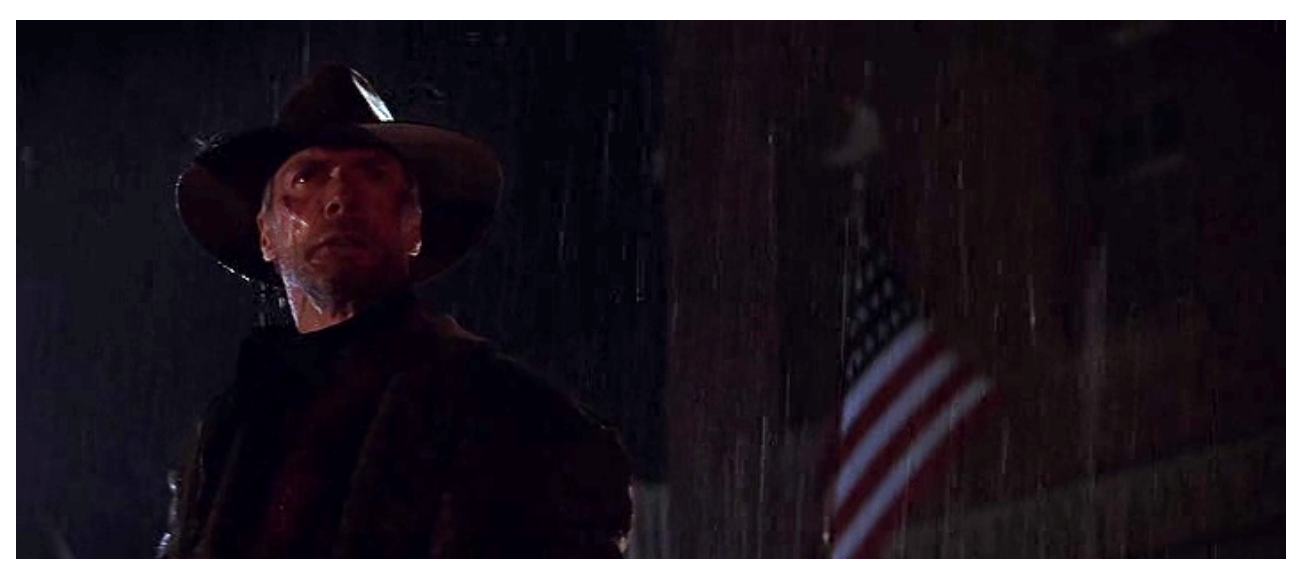

F5. Fotograma de Sin perdón

Esta mirada crítica de la sociedad americana es síntoma de la pérdida de la inocencia de sus ciudadanos. Los asesinatos de sus presidentes han

4 Comprendiendo las fechas en las que está ambientada la obra, Bob "el inglés" se refiere a los asesinatos del presidente James A. Garfield, muerto en 1881 y Abraham Lincoln, asesinado en 1865 . 
provocado la pérdida de su figura paternal. Ello ha traído consigo que sus autores dibujen héroes sin escrúpulos y de moralidad cuestionable. Todo esto son indicios de una sociedad a la que se ha educado tomando como ejemplo a auténticos pistoleros, los cuales fueron objeto de leyenda y, por ende, ejemplos a seguir para la ciudadanía. Algunos de estos hombres fueron tratados como a héroes, hombres de bien. Nada más lejos de la realidad, pues tal y como Eastwood lo proyecta, la frontera entre el mito y la realidad la crean los promotores de leyendas, en otras palabras, escritores, artistas y cineastas. La ceguera axiológica toma forma de miopía en los personajes de Kid y Beauchamp. Ellos, al principio, no son capaces de distinguir lo real de lo admirado, su difuminada moral queda clara ante la exposición de la violencia.

\section{Referencias bibliográficas}

Anson Vaux, S. (2012). The ethical vision of Clint Eastwood. Michigan, United States of America: Wm. B. Eerdmans Publishing Co.

Astre, G. A. \& Hoarau, A. P. (1986). El universo del wéstern. Madrid: Fundamentos.

Benoliel, B. (2007). El libro de Clint Eastwood. París: Cahiers du cinéma.

Buscombe, E. (2004). Unforgiven. London: British Film Institute.

Cook, C. M. (2012). The hero and villain binary in the western film genre (tesis doctoral). Massey: Massey University of New Zealand.

Gómez Tarín, F.J. (2010) El análisis de textos audiovisuales. Significación y sentido. Santander: Shangrila Textos Aparte.

Gonzálvez Vallés, J. E. (2013). El estilema autorial en el cine de Clint Eastwood (tesis doctoral). Madrid: Universidad Complutense de Madrid.

Greenberg, H. R. (1993). Unforgiven. (A. Martin, Ed.) Film Quarterly, 46(3), 53-56.

Ingrassia, C. (1998). Writing the West: Iconic and Liberal Truth in Unforgiven. Literature Film Quarterly, 26(1), 53-59.

Pippin, R. (2009). What is a western ? Politics and Self- Knowledge in John Ford's The Searchers. Critical inquiry, 35(2), 223-246.

Schickel, R. (2010). Clint Eastwood. Una retrospectiva. Barcelona: Art Blume.

Tibbets, J. C. (1993). Clint Eastwood and the Machinery of Violence. Literature Film Quarterly, 21(1), 10-19. 
Zrnijewsky, B. y Pfeiffer, L. (1994). Todas las películas de Clint Eastwood. Barcelona: RBA Editores.

\section{Filmografía}

Eastwood C. (1992). Unforgiven. Estados Unidos. America Film / Malpaso.

Ford, J. (1962) The man who shot Liberty Valance. America Film / Paramount Pictures. 